\title{
Determination of hedonic hotel room prices with spatial effect in Antalya
}

\section{Determinación de precios hedónicos de habitación de hotel con efecto espacial en Antalya}

Fusun YalCin*

Mehmet MerT*

\begin{abstract}
The purpose of the study is to create a hedonic price model containing spatial effect by identifying the accommodation facilities' characteristics that affect the room rates in Antalya (Turkey) area. In this context, the data of 1444 hotels in Antalya was obtained. Since there was a spatial relationship between them, a spatial regression model was proposed. Explanatory spatial data analysis was applied to variables by stepwise regression. The Hedonic Price Model was established using Spatial Lag Model and it reveals that it is applicable to similar studies.
\end{abstract}

Keywords: exploratory spatial data analysis, spatial econometrics, statistics, spatial autocorrelation, hedonic pricing model.

\section{Resumen}

El propósito de este estudio es identificar los factores que afectan el precio de la habitación hotelera en Antalya y crear un modelo de regresión hedónica. Para este propósito, se han seleccionado 1444 hoteles en Antalya. Puesto que estos hoteles están relacionados espacialmente, se ha propuesto un modelo de regresión espacial. Se aplicó la regresión paso a paso (stepwise) a las variables del análisis espacial. El modelo de regresión hedónica se ha construido según el modelo Lag o de retardo espacial (Spatial Lag Model), revelando que es posible utilizar dicho método en estudios similares.

Palabras clave: análisis exploratorio de datos espaciales, econometría espacial, estadística, autocorrelación espacial, modelo de regresión hedónica.

\footnotetext{
*Akdeniz University, Turquía, correos-e: fusunyalcin@akdeniz.edu.tr, mmert@akdeniz.edu.tr
} 


\section{Introduction}

The pricing studies are an important strategy in the economics (Papatheodorou et al., 2013). The consumers can evaluate the prices of the products, compare the same products, and assess them relative to each other to match the quality and the price (Brassington and Pettitt, 2007). In tourism sector, there are many characteristics that affect room rates. The room pricing decisions are quite complex. For a manager, it is very important to determine how the room rates and hotel features are perceived by the consumer (Chen and Rothschild, 2010). The hedonic price model describes the relationship between the room rates and the features of the hotel (Falk, 2008). The scientific studies on the hedonic pricing for the rooms and the factors affecting these pricings at the accommodation facilities in the tourism sector have gained importance in recent years (Papatheodorou et al., 2013; Chen and Rothschild, 2010; Rigall-I-Torrent et al., 2011). Knowing the factors affecting the room pricing as well as being aware of the customer preferences and their behaviors are very important to improve service quality (Baddeley, 2017; Li et al., 2017; Zhang et al., 2011).

Especially, the determination of the factors affecting the room rates of the accommodation facilities and examining their spatial relationship using statistical methods are among the major criteria in pricing (RigallI-Torrent et al., 2011). The spatial analyses for an accommodation facility and scientific studies representing only a small area can be frequently seen in the literature. However, the scientific studies that represent larger areas or regions are scarce.

Antalya region, which has been determined as the study area, hosts a large number of domestic and foreign tourists in the four seasons of the year. With its natural and historic monuments and cultural richness, it attracts the attention of the tourists. The city, as a region, hosts the tourists who are engaged in different activities related to the sea, congress, health, sports, etc. The number of the accommodation facilities increases day by day to meet the intense demand of the tourists; thus, it leads the competitive environment to grow. The facilities have to increase the number of their customers and overtake other competitors. Thus, the way to increase the number of customers is very important. Especially, the most important factor affecting the number of the customers in the tourism sector is the room rates offered by the facility, its features, and location. Therefore, a detailed study including the room rates, features, locations, distances to the sea, and the features of the beach of the accommodation facilities in Antalya province was required.

In line with this scope, the aim of the study is to determine the features of the accommodation facilities which are present in the Antalya province, 
particularly those on the coastal zone and their proximity to the beach, in order to analyze the impacts of these features on the room rates, and to determine the changes based on their spatial attributes. Examining the spatial distribution of the room rates of the accommodation facilities and determining the regions and variables that are affected will be useful for the regional managers and operators. Determining how and to what extent the variables affect the room rates of the tourism facilities will contribute significantly to the research on tourism marketing, and the studies on room pricing.

\section{Literature review}

The purchasing behaviors of consumers are complex. Because humans need to show a heterogeneous structure, the consumers behave differently. Since the consumer behavior is important for determining the room rates, the hedonic price model is also very important (Papatheodorou et al., 2013, Chen and Rothschild, 2010; Rigall-I-Torrent et al., 2011). The hedonic price model is a tool that is used to develop strategies for the hotels as well as to meet the needs of the consumers. The hedonic price model, which has been successfully applied in the tourism sector, has generally been effective in analyzing the prices of houses (Kördiş et al., 2014; Uyar and Yayla, 2016; Kaya and Atan, 2014). While the hedonic price model is commonly used in the tourism sector worldwide, its use is very limited in Turkey. One of them is the study carried out in Erzurum (Turkey). As an empirical study, a total of 26 variables were identified and 15 of them were determined to have an impact on the hotel room rates (Işı1k and Bilici, 2017).

The empirical studies using conventional regression methods have revealed that the number of stars, location, and the age of the facility have explained the room rates of the accommodation facilities (Zhang et al., 2011; Lancaster, 1966; Rosen, 1974). However, considering their spatial relationships, the conventional regression methods used in room pricing has been observed to be insufficient to estimate the room rates (Zhang et al., 2011; Lancaster, 1966). Therefore, it is known that geographically weighted regression (GWR) analysis is a more effective method for increasing the explanatory power of the pricing model (Zhang et al., 2011). The reduction in the occupancy rate of the accommodation facilities is not only due to economic problems (Sánchez-Martín et al., 1998). The occupancy rate is affected by oversupply, adverse weather conditions, inadequate promotion, the mismatch between the tourist potential of the region and the accommodation supply (Sánchez-Martín et al., 1998). 
Since conventional statistical models generally can consider the spatial aspect of the tourism sector, these models are inadequate to analyze these non-conforming situations (Sánchez-Martín et al., 1998; Zhang et al., 2011). Including a spatial component into the classical statistical analyses is important to shape tourism in the regions. The technical data such as supply and demand balance in the tourism sector will be distributed within it and the fields affected by the related variables will be highlighted. Thus, their significant spatial distribution will be determined (Sánchez-Martín et al., 1998). Therefore, this study suggests the use of statistical models based on spatial parameters that are rarely used in the scientific literature.

Taking into account the beach features along the coast of Catalonia in Spain and the locations of the accommodation facilities on this beach, Rigall-I-Torrent et al. (2011) developed a model and used it to determine how the features of the beach and the location of the facility change the room rates. The study, which was conducted at the accommodation facilities on the coast, reveals that the characteristic features of the region, such as the safety and the cleanliness of the coast on which the facility is located, having a swimmable beach and the blue flag, as well as the special services offered by the facility, such as sports activities, features of the swimming pool, and accommodation services, play an important role among the issues that a tourist takes into consideration in the selection of the accommodation facility. In his book on tourism, Bull (1998) points out that the location of the facility is important for pricing of the room of the accommodation facilities.

Moreover, the accommodation enterprises have expressed that the distance between the facility and the beach has an impact on room pricing. Selecting the Halkidiki region in Greece as the study area, Latinopoulos (2018) tried to examine the impact of the sea view on the room rates as well as other structural and spatial attributes in his study. As a result, the study revealed that the sea view has an important spatial variability in terms of its impact on the room rates (Latinopoulos, 2018). Wang et al. (2018) noted that China's high-speed rail networks have effectively changed the spatial arrangements of the urban tourism in China. He used spatial analysis in this study. As a result, the study proposes 19 tourism clusters with 6 Class- 1 and, 21 Class- 2 tourism economic zones. He suggests a tourism spatial structure by using strategies to optimize China's tourist location (Wang et al., 2018). Hajilo et al. (2017) examined the spatial analysis of the distribution of small facilities in the eastern part of the Ghilan province by underlining the tourism in mountainous areas. And finally, they have found that the distribution of the facilities for all kinds of activities is much higher in plains and valleys compared to the hills and mountainous areas. In their study, Kostakis and 
Theodoropoulou (2017) have shown the empirical proof of the spatial data analysis of the relationship between the tourism and economic growth.

This study aims to propose a spatial hedonic price model that involves the location of the enterprise and the characteristics of its beach in determining the room rates for the accommodation enterprises in the Antalya area.

\section{Method}

\subsection{Study Area}

Antalya province, which is the region selected as the sample area of the study, is located in the south of Turkey on the Mediterranean coast with an area of $20,723 \mathrm{~km}^{2}$. The coastal strip on the Mediterranean Sea is about $630 \mathrm{~km}$. With the population of 2,364,396; it is the $5^{\text {th }}$ largest province of Turkey today (TUIK, 2005). Before the Turks, Antalya was called Adalya which was named after Attalos II, the king of Pergamum. Antalya has 19 districts and the most important source of revenue in the city is tourism. Attracting attention with the sea and its history in the summer, Antalya hosts congress events as well as sports camps in the winter with its warm weather (MCT, 2003). Alanya, Demre, Finike, Gazipaşa, Kaş, Kemer, Konyaalt1, Kumluca, and Manavgat districts, which are located on the coast of the Mediterranean Sea, are the most important districts in terms of tourism. The population of the study is the accommodation facilities located on the coast in the province of Antalya. The frequency tables of the accommodation facilities have been prepared in line with the regions received from the website of the data. The regions with less than 10 frequencies were combined with the nearest neighbor. Yeniköy, Manavgat, Beycik, and Davazlar have not been included in the scope of the study since they are not on the coast. The accommodation facilities in Kiriş have been combined with those in Çamyuva district; the ones in Çamyolu have been combined with those in Mahmutlar district. The accommodation facilities in Kapaklı, Kaleüçağız, Karaöz, and Yeniceköy regions have been combined with those in the Adrasan region. Those in Konyaaltı region have been combined with those in Antalya region. In accordance with these arrangements, the number of the facilities is shown in table 1 and the density map is given in figure 1 . 
Table 1

Touristic regions and their beach features

\begin{tabular}{|c|c|c|c|c|c|}
\hline $\begin{array}{l}\text { Touristic } \\
\text { Region }\end{array}$ & $\begin{array}{l}\text { Beach } \\
\text { Name }\end{array}$ & Sand Type & Beach Type & $\begin{array}{l}\text { Beach Length } \\
\text { (M) }\end{array}$ & $\begin{array}{c}\text { Beach Width } \\
\text { (M) }\end{array}$ \\
\hline Adrasan & Adrasan & $\begin{array}{l}\text { Fine, medium, } \\
\text { coarse }\end{array}$ & Urban & 1750 & 10 \\
\hline Alanya & Alanya & $\begin{array}{l}\text { Fine, medium, } \\
\text { coarse }\end{array}$ & Semi-Urban & 14000 & 75 \\
\hline \multirow[t]{7}{*}{ Antalya } & $\begin{array}{l}\text { Kadınlar Plajı/ } \\
\text { Sarısu }\end{array}$ & Fine, medium & Semi-Urban & 1500 & 60 \\
\hline & Konyaaltı & Fine, medium & Urban & 7500 & 40 \\
\hline & Falez 1 & Coarse & Urban & 1600 & 1 \\
\hline & Kaleiçi & Medium & Urban & 1500 & 1 \\
\hline & Falez 2 & Coarse & Semi-Urban & 10000 & 1 \\
\hline & Lara & Fine & Semi-Urban & 5200 & 75 \\
\hline & Kundu & Fine & Semi-Urban & 5600 & 75 \\
\hline \multirow[t]{2}{*}{ Avsallar } & İncekum & Fine, medium & Semi-Urban & 3500 & 40 \\
\hline & Avsallar & Fine, medium & Semi-Urban & 3200 & 30 \\
\hline Beldibi & Beldibi & Fine, medium & Semi-Urban & 7300 & 30 \\
\hline \multirow[t]{5}{*}{ Belek } & Kumköy & Fine & Semi-Urban & 4800 & 100 \\
\hline & Belek & Fine, medium & Semi-Urban & 14000 & 60 \\
\hline & Boğazkent & Fine, medium & Semi-Urban & 4150 & 60 \\
\hline & Denizkent & Fine, medium & Semi-Urban & 8300 & 75 \\
\hline & Çolaklı & Fine, medium & Semi-Urban & 6700 & 100 \\
\hline Çıralı & Çıralı & Fine, medium & Semi-Urban & 3200 & 85 \\
\hline \multirow[t]{5}{*}{ Finike } & Finike & Fine, medium & Semi-Urban & 7000 & 50 \\
\hline & Hasyurt & Fine, medium & Semi-Urban & 2500 & 50 \\
\hline & Kavakköy & Fine, medium & Semi-Urban & 2000 & 50 \\
\hline & Beykonak & Fine, medium & Semi-Urban & 4300 & 100 \\
\hline & Mavikent & Fine, medium & Semi-Urban & 5500 & 100 \\
\hline Göynük & Göynük & Fine, medium & Semi-Urban & 5100 & 40 \\
\hline Kaleucagız & Kaleüçağız & Coarse & Semi-Urban & 200 & 1 \\
\hline Kalkan & Kalkan & Coarse & Semi-Urban & 4000 & 10 \\
\hline Kas & Kaş & Coarse & Semi-Urban & 5500 & 10 \\
\hline \multirow[t]{3}{*}{ Kemer } & Kemer & Fine, medium & Semi-Urban & 4500 & 15 \\
\hline & Kiriş & Fine, medium & Semi-Urban & 2150 & 60 \\
\hline & Çamyuva & $\begin{array}{l}\text { Fine, medium, } \\
\text { coarse }\end{array}$ & Semi-Urban & 3100 & 50 \\
\hline \multirow[t]{2}{*}{ Kızılot } & Kizılot & Fine, medium & Urban & 4700 & 100 \\
\hline & Çenger & Fine, medium & Urban & 4400 & 100 \\
\hline
\end{tabular}


Table 1 (Continuation)

\begin{tabular}{llllcc}
\hline $\begin{array}{c}\text { Touristic } \\
\text { Region }\end{array}$ & \multicolumn{1}{c}{$\begin{array}{c}\text { Beach } \\
\text { Name }\end{array}$} & Sand Type & Beach Type & $\begin{array}{c}\text { Beach Length } \\
(M)\end{array}$ & $\begin{array}{c}\text { Beach Width } \\
\text { (M) }\end{array}$ \\
\hline \multirow{4}{*}{ Konaklı } & Kizılagac & Fine, medium & Urban & 5600 & 50 \\
& Türkler & Fine, medium & Semi-Urban & 4000 & 50 \\
& Payallar & Fine, medium & Semi-Urban & 4500 & 40 \\
& Konaklı & Fine, medium & Semi-Urban & 8500 & 30 \\
\multirow{2}{*}{ Mahmutlar } & Mahmutlar & Fine, medium & Urban & 5150 & 75 \\
& Kargıcak & Fine, medium & Urban & 2000 & 50 \\
\multirow{2}{*}{ Okurcalar } & Okurcalar & Fine, medium & Semi-Urban & 8000 & 40 \\
Patara & Patara & Fine & Urban & 6700 & 100 \\
Side & Side & Fine, medium & Semi-Urban & 10000 & 60 \\
& Manavgat & Fine, medium & Semi-Urban & 5000 & 60 \\
Tekirova & Tekirova & Fine, medium & Semi-Urban & 3700 & 50 \\
\hline
\end{tabular}

Source: own elaboration based on Yalcin (2016).

\section{Figure 1}

\section{The location of Antalya region}
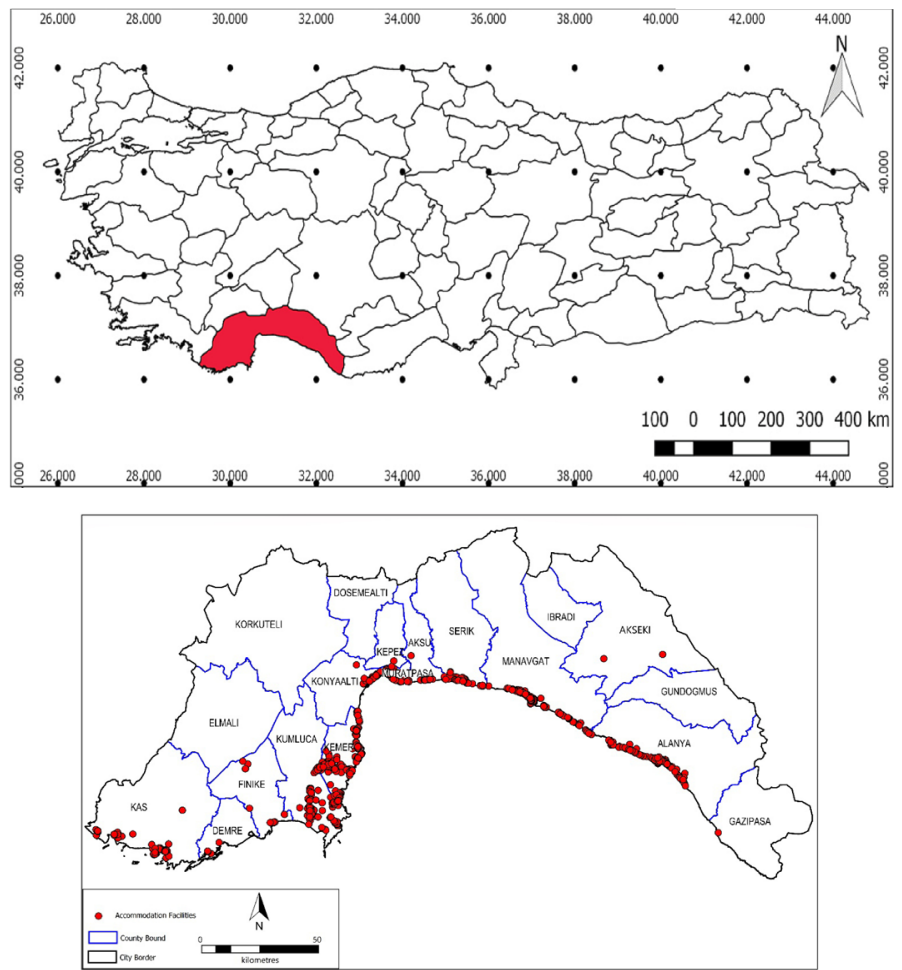

Source: own elaboration, generated using QGIS software. 


\subsection{Data}

The biggest challenge in monitoring price changes is accessing the sector's dataset which is not available. The internet sites have been commonly used as a data source as they facilitate access to large datasets. For example; Bulchand-Gidumal et al. (2013) seems to have examined 1773 customer reviews from TripAdvisor site and Melián-González et al. (2013) have studied 16,680 data from the eWOM site. In this study, one of the world's most widely used travel sites was used to prepare the dataset. This website offers a booking tool as well as an online catalog for information about the hotels, resorts, and pensions with various features. The facility features are populated with the information obtained from the website. The arrangement of these features has made it easier to group them.

The room rates of the accommodation facilities, which made up our sample, were acquired from the relevant website in the first week of August 2015, for one-day accommodation in the first week of August 2015. The room rates for just the standard rooms of the same categories were obtained and not for other categories. Thus, the problem of the price variability that can arise from the fact that the website offers different prices on different days has been avoided.

The room rates, which have been defined as the dependent variable, are the lowest room rates offered by the accommodation facilities. During the acquisition of the room rates, special discounts made by the website were not taken into consideration.

The attributes of the facilities were acquired from the website, and their locations were acquired by using online-map services between MarchJune 2016. 1444 data about the accommodation facilities were compiled and prepared for the statistical analysis methods. The attributes (the characteristics of the accommodation facilities) were related to the vector data of the point features (the coordinates of the accommodation facilities) in this study. Table 2 shows the attributes i.e. the variables of the model.

Since the room rates are not stable but change every week, collecting data from 1444 hotels within a week was a very tedious process.

\subsection{Exploratory Spatial Data Analysis}

The spatial data have specific coordinates on the map. The methods developed for the analysis of these data arise from the idea that the close entities can have similar values and cannot be independent of each other (Anselin, 1988). Exploratory Spatial Data Analysis (ESDA) examines the existence of the spatial relationships and certainly focuses on the spatial characteristics of the data (LeSage, 1999). Two kinds of problems arise 


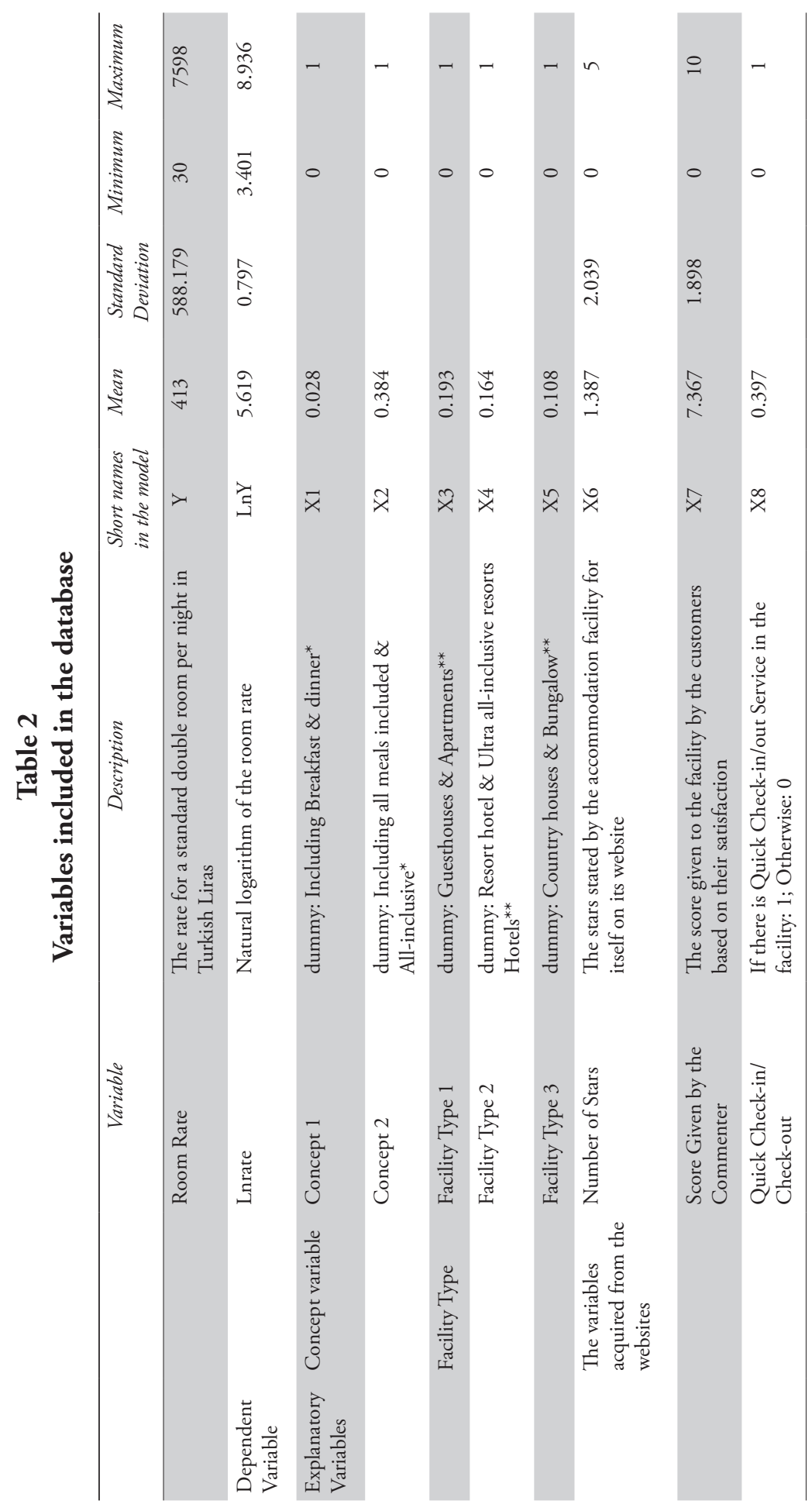




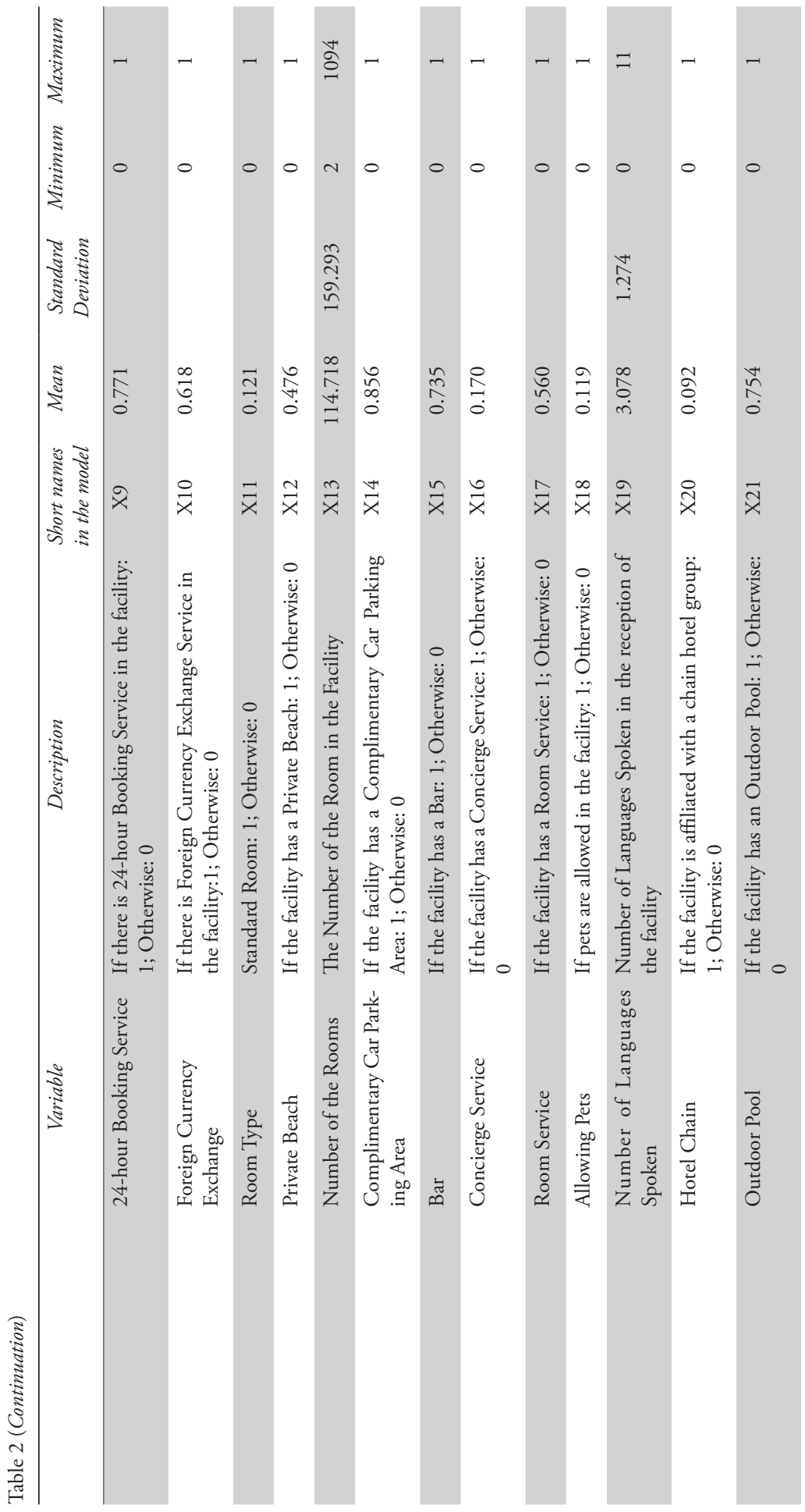




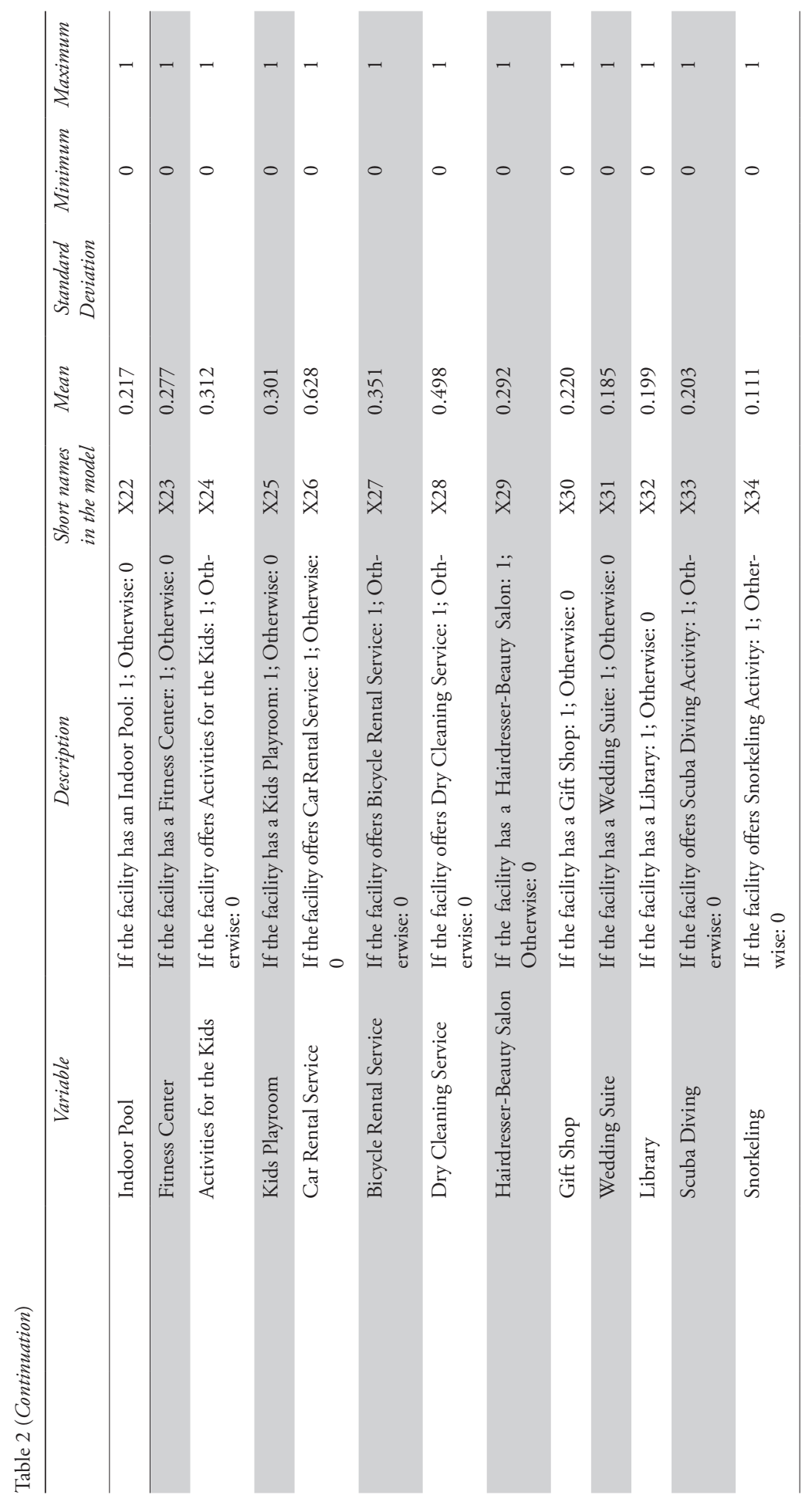




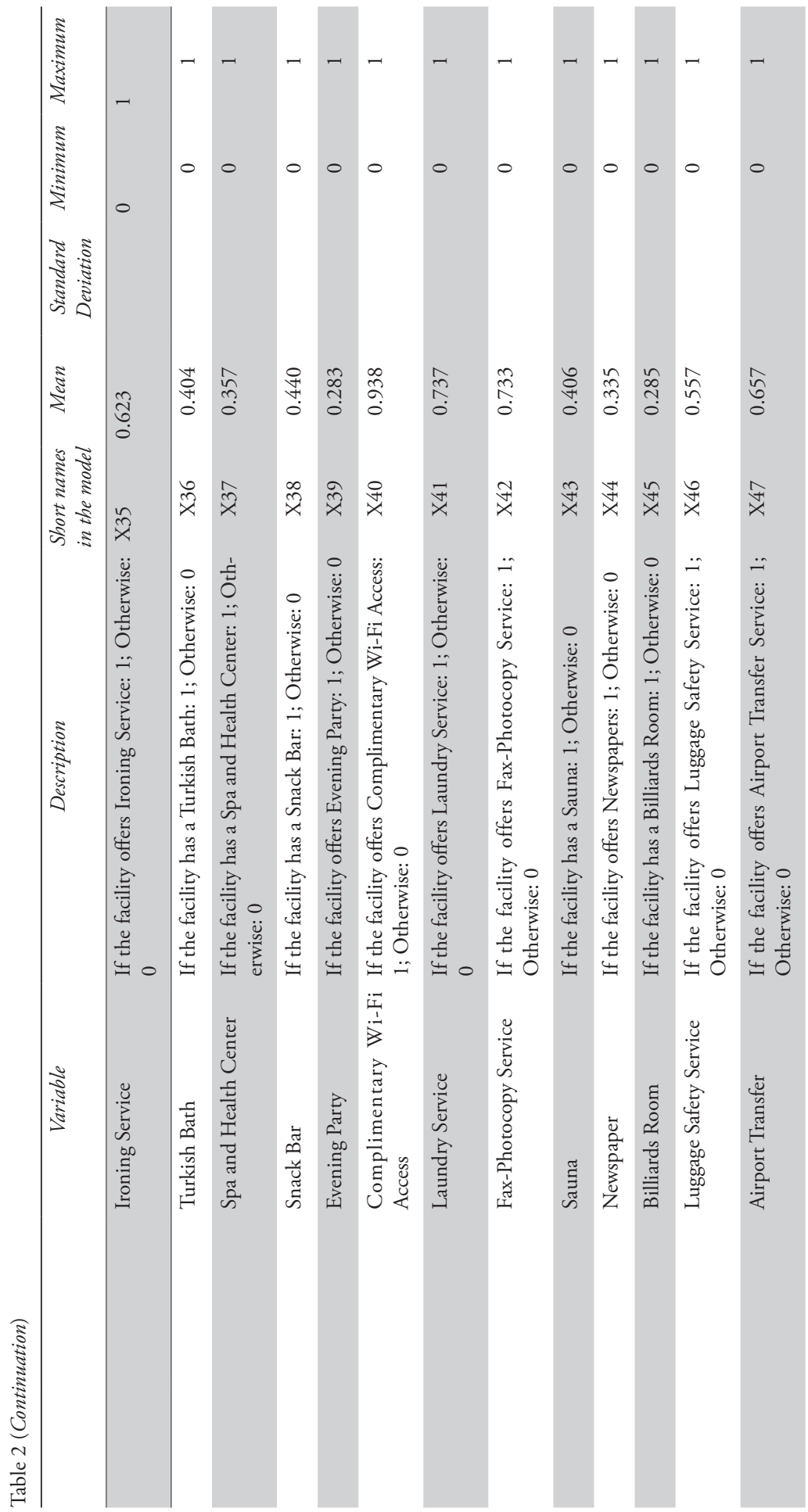




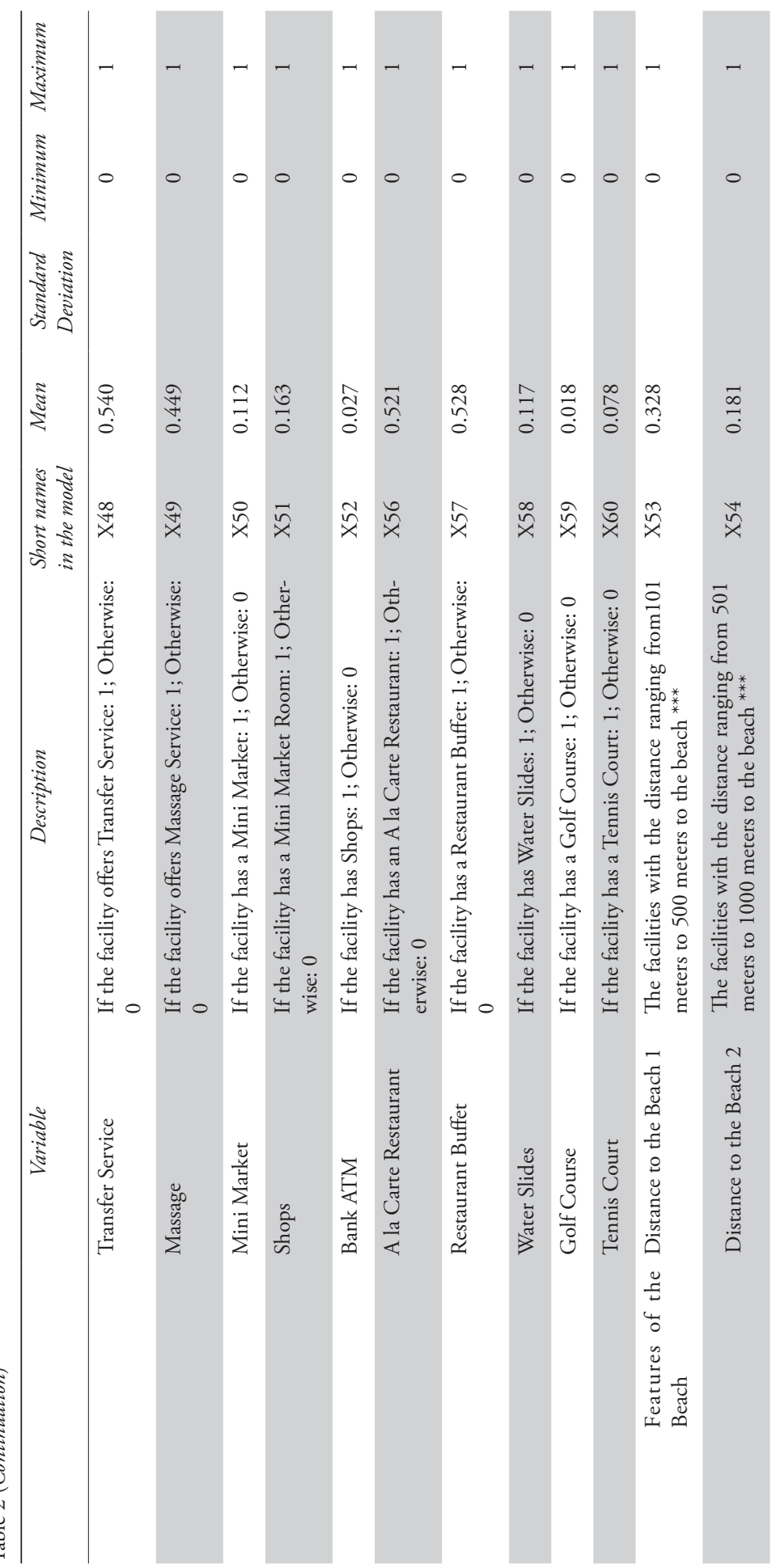




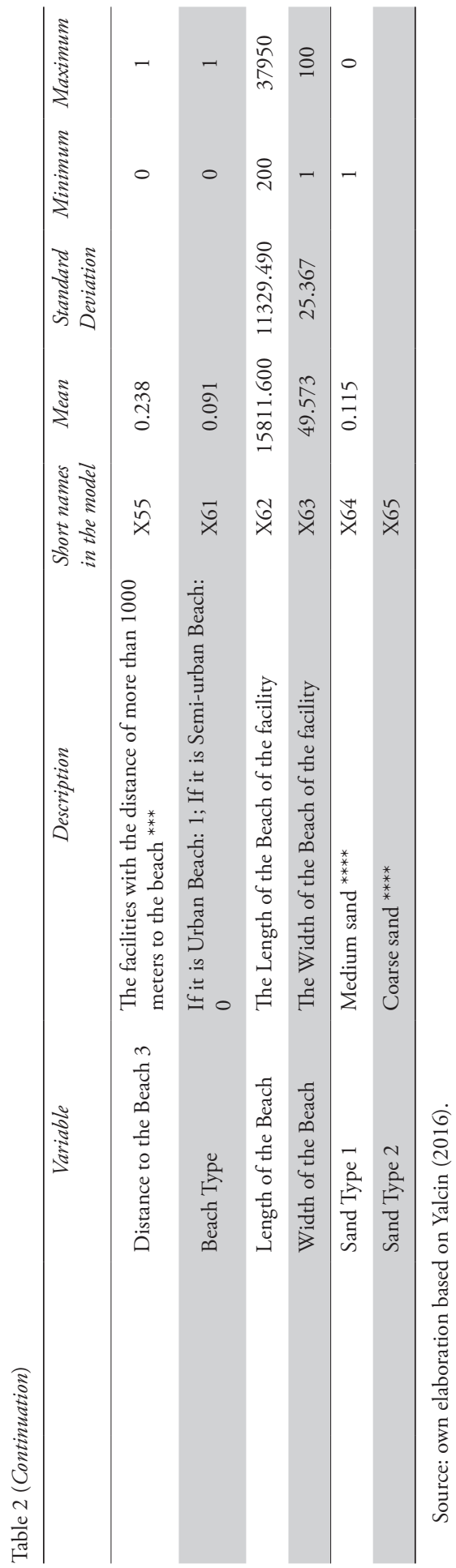


when studying with spatial data. The first one is the spatial autocorrelation between the observations, and the second one is the spatial heterogeneity of the designed relationship. In the presence of the spatial autocorrelation, the exploratory spatial data analysis is used, whereas the classical data analysis methods, such as the least squares regression, should be used in the absence of spatial autocorrelation. The predictors will lose their effectiveness on the obtained parameter estimations when the spatial autocorrelation is ignored (Basu and Thibodeau, 1998).

The spatial autocorrelation is categorized into two groups as global and local. The Local Indicators of Spatial Association (LISA) is used to measure the relationship between a specific area and the areas (neighbors) defined by the researchers as neighbors. The global spatial autocorrelation survey provides information about the spatial model of the whole area (Ord and Getis, 1995; Anselin, 1995). The first studies on spatial autocorrelation were carried out by Geary (1954) and they defined the weight matrix simply as $w_{i j}=1$ if they are neighbors, and $w_{i j}=0$ if they are not (Anselin et al., 2004). In studies on spatial data, the spatial neighborhood matrix is defined to explain the spatial neighborhood relationship, i.e. the autocorrelation. These weights represent a measure of diffusion or interaction. The spatial econometric model is then predicted based on these weights (Anselin et al., 2004).

Since the location has strong impacts, this approach is appropriate for the room pricing model in accommodation facilities. In other words, there is a spatial autocorrelation at the room rates of the accommodation facilities. Taking the spatial structure of data into account, the spatial regression methods are used to solve this problem.

\subsubsection{Spatial Autocorrelation}

The exploratory statistics showing the presence of spatial autocorrelation between the analysis units and their neighbors need to be addressed at the beginning of the spatial data analysis studies. The most commonly used one among them is the Moran-I statistics (Moran, 1950). The Moran-I statistics is used to determine the linear relationship between the mean values of an observation and its neighbors (Ward and Skrede Gleditsch, 2008).

The Moran-I statistics, which is based on the assumption that the errors are normally distributed, is shown in Equation 1 (Anselin, 1992):

$$
I=\frac{n}{S_{0}} \frac{\sum_{i=1}^{n} \sum_{j=1}^{n} w_{i j}\left(x_{i}-\dot{x}\right)\left(x_{j}-\dot{x}\right)}{\sum_{i=1}^{n}\left(x_{i}-\dot{x}\right)^{2}}
$$


where $n$ denotes the number of observations. The $S_{0}$ here is stated in Equation 2:

$$
S_{0}=\sum_{i=1}^{n} \sum_{j=1}^{n} w_{i j}
$$

When the Moran-I value is close to +1 , it indicates strong positive spatial dependence and when it is close to -1 it indicates strong negative spatial dependence. And, it indicates no spatial dependency when it is close to 0 . The local spatial autocorrelation values can be measured by using LISA (Local Indicators of Spatial Association) analysis. LISA calculates a separate spatial autocorrelation value for each region. It gives results in four categories, namely high-high, low-low, high-low, and lowhigh (Anselin, 1995).

In this study, Global Moran-I and LISA methods were used to measure the spatial autocorrelation of the room rates.

\subsubsection{Spatial Regression Models}

The spatial autocorrelations are considered in the spatial regression models. The multiple linear regressions will constitute both an initial and a benchmarking system for the spatial models. A general model that does not involve spatial relationships is stated as in Equation 3 (Elhorst, 2010):

$$
Y=\alpha l_{n}+X \beta+\varepsilon
$$

Manski (1993) reveals that three types of interaction effects may explain why an observation is influenced by the neighboring observations. (i) Endogenous Effects: The individuals may tend to act in line with the group behavior. (ii) Exogenous Effects: The individuals may tend to behave in a manner similar to the external characteristics that make up the group. (iii) Correlated Effects: The individuals in the same group may tend to behave in the same way because they have similar characteristics, or they are exposed to similar environmental impacts. The point to be noted here is the fact that the endogenous and the exogenous effects arise from other spatial units, but the correlated effect arises due to environmental factors.

Elhorst (2010) expresses the most general spatial regression model which involves these three effects in Equation 3a:

$$
\begin{gathered}
Y=\rho W Y+\alpha l_{n}+X \beta+W X \theta+u \\
u=\lambda W u+\varepsilon
\end{gathered}
$$


Here;

$W Y$ denotes the endogenous interaction effects among the dependent variables,

$\rho W Y$ denotes the endogenous interaction effects among the independent variables,

$W X$ denotes the exogenous interaction effects among the independent variables, and

$W u$ denotes the spatial dependence between the disturbance of the neighboring spatial units (Elhorst, 2010).

As the other parameters of the model, $\rho$ denotes the spatial autoregressive coefficient, $\lambda$ denotes the spatial autocorrelation coefficient. $\beta$ and $\theta$ constitute the other parameters in the classical regression model (Elhorst, 2010). Different spatial models can be obtained based on whether the coefficients of $\rho, \lambda$, and $\theta$ are different from zero (Elhorst, 2010).

The Lagrange Multiplier (LM) statistics spatial error model and spatial lag model are denoted as $L M_{E R R}$ and $L M_{L A G}$ and they are stated in Equation 5 and Equation 6 (Anselin, 1995):

$$
L M_{E R R}=L M_{\lambda}=\frac{\left(\frac{\varepsilon^{\prime} W \varepsilon}{\sigma^{2}}\right)^{2}}{\tau}
$$

where $T$ is the trace of the matrix and $L T=\operatorname{tr}\left(\left(W^{\prime} W+W\right) W\right)$ and $\sigma^{2}=\varepsilon^{\prime} \varepsilon$. With a degree of freedom of 1 , this test statistics conform to the $x^{2}$ distribution. Here $L M_{L A G}$ is stated as follows:

$$
L M_{L A G}=L M \rho=\frac{\left(\frac{\varepsilon^{\prime} W}{\sigma^{2}}\right)^{2}}{\left(\frac{(W X b)^{\prime} M(W X b)}{\sigma^{2}}+\operatorname{tr}\left(W^{\prime} W+W 2\right)\right)}
$$

where $M$ is the idempotent matrix and calculated in Equation 7:

$$
M=I W Y-X(\dot{X} X)^{-1} \dot{X}
$$

$b$, which is the coefficient vector, belongs to the Ordinary Least Squares (OLS) predictions. With a degree of freedom of 1 , this statistics asymptotically conforms to the $x^{2}$ distribution (Anselin et al., 1996).

However, the robust transformations are required when both of these tests have significant results. Because these tests may result in an inapplicable OLS model in case there are other spatial effects. For example, if 
the OLS model is decided to be invalid at the end of the test, this may also occur in the presence of a spatial autoregressive model. Similarly, the significance of the test may also arise in the presence of the spatial error model. Therefore, it is possible to determine the model from which the actual spatial effect originates by making robust transformations of the Lagrange Multiplier tests. In case both of the tests are significant, the model of the significant robust test should be predicted as an alternative to the OLS model (Anselin et al., 1996). In this study, which is about the determination of the factors having an impact on room rates of the accommodation facilities, the impacts of the locations of the facilities on the room rates are examined. Therefore, the exploratory spatial data analysis is the most appropriate method for solving the problem of the study.

\section{Estimation Results}

\subsection{The Results of Exploratory Spatial Data Analysis}

Whether the spatial distribution of the room rates of the accommodation facilities shows a clustering or not was examined on the map at first in the exploratory spatial data analysis. Examining the map (figure 2), it has been found that the room rates of the facilities located in close proximity to each other show clustering. The regions where the rates are similar have the same color. The darkest color seen on the map shows the regions with the highest prices. For example, "Antalya and Belek", "Kemer and Göynük", and "Adrasan, Çıralı, Tekirova, and Olimpos" regions show clustering in terms of room rates. The facilities with the highest room rates are in the Antalya, Belek, and Mahmutlar regions.

Although it points out the existence of a spatial relationship, Moran-I scatter diagram developed by Moran (1950) was examined to state the existence of the relationship certainly. As a result, a positive autocorrelation between the room rates and those of their neighbors have been determined (figure 3).

At the end of these examinations, it was determined that there is a spatial relationship between the room rates of the accommodation facilities in the Antalya region.

Considering the results of the LISA clustering map (figure 1) in terms of the room rates, it seems that there is significant spatial clustering in the neighboring locations. It has been found that there is a positive spatial relationship between the room rates of the 161 accommodation facilities in the red regions (Patara, Finike, Olimpos, Alanya) and they affect each other positively. A positive autocorrelation has been determined between 
Figure 2

Spatial Distribution of the Room Rates and the LISA Analysis Map of the Accommodation Facilities in Antalya
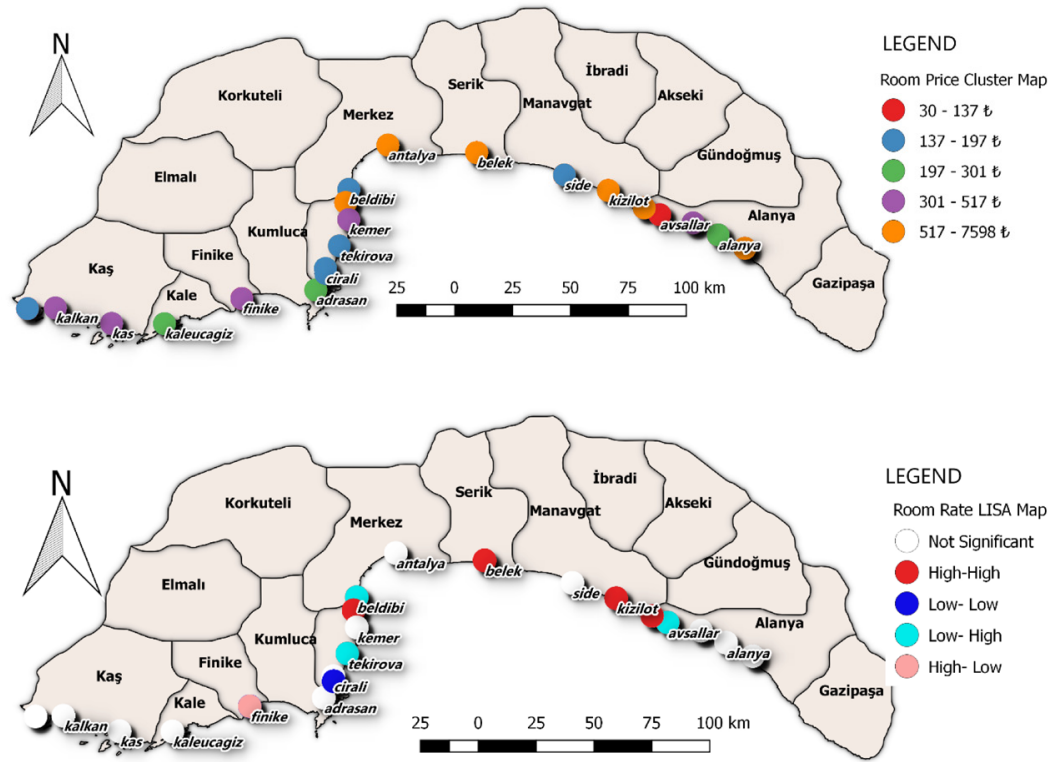

Source: own elaboration, generated using QGIS software.

Figure 3

Moran Scatter Diagram of the Room Rates of the Accommodation Facilities in Antalya

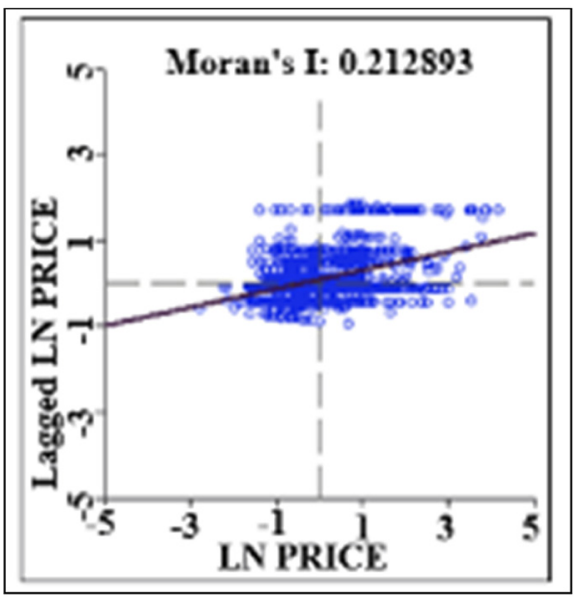

Source: own elaboration, made with GeoDa software. 
the room rates of the 48 accommodation facilities in the blue regions (Kalkan, Kaş, Tekirova, Göynük, Beldibi, Belek, Kızılot, Okurcalar, Mahmutlar), however, the room rates in these regions affect each other negatively. Moreover, a negative autocorrelation has been observed between the room rates of 54 facilities in the low-high zones and 11 facilities in the high-low zones. A clearer image of the map was prepared by using QGIS software in accordance with the values calculated in the GeoDaSpace software.

\subsection{Estimating Ordinary Least Squares (OLS) Regression Model}

Once it has been decided that there is a spatial interaction according to the (figure 3), LM tests have been used to examine the variables causing this spatial relationship. A hedonic pricing model was developed to determine whether there is a spatial relationship between the room rates of the accommodation facilities in 21 regions and then the residuals were obtained by using OLS estimation. The hedonic room pricing model to be predicted is given in Equation 8:

$$
\begin{aligned}
Y=\beta_{0}+\beta_{1} X 1 & +\beta_{2} X 2+\beta_{3} X 3+\beta_{4} X 4+\beta_{5} X 5+\beta_{6} X 6+\beta_{7} X 7+\beta_{8} X 8+\beta_{9} X 9+\beta_{10} X 10+\beta_{11} X 11 \\
& +\beta_{12} X 12+\beta_{13} X 13+\beta_{14} X 14+\beta_{15} X 15+\beta_{16} X 16+\beta_{17} X 17+\beta_{18} X 18+\beta_{19} X 19 \\
& +\beta_{20} X 20+\beta_{21} X 21+\beta_{22} X 22+\beta_{23} X 23+\beta_{24} X 24+\beta_{25} X 25+\beta_{26} X 26+\beta_{27} X 27 \\
& +\beta_{28} X 28+\beta_{29} X 29+\beta_{30} X 30+\beta_{31} X 31+\beta_{32} X 32+\beta_{33} X 33+\beta_{34} X 34+\beta_{35} X 35 \\
& +\beta_{36} X 36+\beta_{37} X 37+\beta_{38} X 38+\beta_{39} X 39+\beta_{40} X 40+\beta_{41} X 41+\beta_{42} X 42+\beta_{43} X 43 \\
& +\beta_{44} X 44+\beta_{45} X 45+\beta_{46} X 46+\beta_{47} X 47+\beta_{48} X 48+\beta_{49} X 49+\beta_{50} X 50+\beta_{51} X 51 \\
& +\beta_{52} X 52+\beta_{53} X 53+\beta_{54} X 54+\beta_{55} X 55+\beta_{56} X 56+\beta_{57} X 57+\beta_{58} X 58+\beta_{59} X 59 \\
& +\beta_{60} X 60+\beta_{61} X 61+\beta_{62} X 62+\beta_{63} X 63+\beta_{64} X 64+\beta_{65} X 65+u
\end{aligned}
$$

In order to obtain the most suitable model, a stepwise regression was carried out to create a new model with statistically significant variables. The estimated OLS model with significant coefficients is shown in Equation 9:

$$
\begin{aligned}
& Y=\beta_{0}+\beta_{1} X 21+\beta_{2} X 52+\beta_{3} X 41+\beta_{4} X 53+\beta_{5} X 54+\beta_{6} X 55+\beta_{7} X 19+\beta_{8} X 42+\beta_{9} X 59+ \\
& \beta_{10} X 44+\beta_{11} X 2+\beta_{12} X 64+\beta_{13} X 65+\beta_{14} X 49+\beta_{15} X 13+\beta_{16} X 11+\beta_{17} X 12+\beta_{18} X 56+ \\
& \beta_{19} X 57+\beta_{20} X 43+\beta_{21} X 38+\beta_{22} X 63+\beta_{23} X 4+\beta_{24} X 5+\beta_{25} X 35+\beta_{26} X 6+\beta_{27} X 20+u
\end{aligned}
$$

There is not a multicollinearity problem in the model estimated by stepwise regression. The highest value of VIF (Variance Inflation Factors) is 2.66. Since there are so many observations, there is no need to examine the normality assumption under the central limit theorem. It has been deter- 
mined that there is a heteroscedasticity problem and this problem has been solved by using the White predictor in the spatial lag model in table 3 .

The explanatory variables in the model have been determined to explain about $55 \%$ of the variations in the room rates of the accommodation facilities in the Antalya region.

According to these results, the major variables having a positive impact on the room rates of the accommodation facilities in Antalya province have been determined as having an outdoor pool, a laundry room, a golf course, a snack bar, and offering massage in the facility and having a private beach. While offering ironing service in the facility has a negative impact on the room rate compared to the facilities which do not offer this service, the standard room type has a positive impact on the room rates compared to the other room types. This is because it is the most preferred room type. And also, being close to the sea and the type of the facility are among the important variables.

After the estimation of the hedonic room pricing model by using stepwise OLS regression, the residuals were obtained and the spatial weight matrix was prepared accordingly. The residuals and the spatial weight matrix were used to perform spatial autocorrelation tests. A number of matrices were prepared based on various spatial weights while preparing the spatial weight matrix. The closest k-neighbor matrix (arck10), which is calculated by the arc distance, was preferred to be the most suitable weight matrix. The proximity of the locations of the facilities to each other and being located in the coastal zone of the Mediterranean region have been determined to be important. Furthermore, the Moran-I value, obtained by calculating the Moran-I statistic from OLS regression residuals, was determined to be 0.212 which shows a strong positive spatial dependence.

Both LM (Lag) and LM (Error) tests were determined to be significant at the $1 \%$ significance level. Since the Robust LM (Lag) $<$ Robust LM (Error), the spatial autocorrelation has been interpreted to be the result of the Spatial Lag Model. The results of the Robust Spatial Lag Model estimation are presented in table 3 and table 4.

The spatial models designed based on spatial weight matrix are the Spatial Lag Model (SLM), Spatial Error Model (SEM), the robust versions of these two models Robust LM (Lag), Robust LM (Error), and the Spatial Autoregressive Moving Average (SARMA) model. Firstly, it was tested whether two models were significant compared to the OLS regression model by using LM tests. The LM test results are presented in table 5. The LM test results and the matrix have been obtained by using the GeoDaSpace software. 
Table 3

Parameter summary of OLS, Stepwise OLS, and SLM Estimation results

\begin{tabular}{|c|c|c|c|}
\hline Variable & $O L S$ & Stepwise OLS & $S L M$ \\
\hline CONSTANT & $5.300^{* * *}$ & $5.674^{* * *}$ & $4.375^{* * *}$ \\
\hline X9 & 0.033 & & \\
\hline $\mathrm{X} 8$ & -0.048 & & \\
\hline $\mathrm{X} 7$ & 0.011 & & \\
\hline $\mathrm{X} 65$ & 0.107 & $0.132^{*}$ & -0.011 \\
\hline X64 & $-0.120^{*}$ & $-0.121^{* * *}$ & $-0.189^{* * *}$ \\
\hline X63 & $-0.001^{*}$ & $-0.002^{* *}$ & $-0.002^{* *}$ \\
\hline X62 & -0.000 & & \\
\hline $\mathrm{X} 61$ & -0.052 & & \\
\hline $\mathrm{X} 60$ & 0.103 & & \\
\hline $\mathrm{X} 6$ & $0.022^{*}$ & $0.025^{* *}$ & $0.024^{* *}$ \\
\hline $\mathrm{X} 59$ & $0.347^{* * *}$ & $0.409^{* * *}$ & 0.167 \\
\hline $\mathrm{X} 58$ & -0.084 & & \\
\hline $\mathrm{X} 57$ & -0.055 & $-0.064^{*}$ & $-0.065^{* *}$ \\
\hline $\mathrm{X} 56$ & $-0.064^{*}$ & $-0.075^{* *}$ & $-0.060^{*}$ \\
\hline $\mathrm{X} 55$ & -0.122 & $-0.128^{* * *}$ & $-0.134^{* * *}$ \\
\hline $\mathrm{X} 54$ & -0.088 & $-0.087^{*}$ & -0.073 \\
\hline $\mathrm{X} 53$ & -0.105 & $-0.109^{* * *}$ & $-0.095^{* *}$ \\
\hline $\mathrm{X} 52$ & -0.155 & $-0.188^{* *}$ & \\
\hline $\mathrm{X} 51$ & 0.029 & & \\
\hline $\mathrm{X} 50$ & 0.000 & & \\
\hline $\mathrm{X} 5$ & $-0.258^{* * *}$ & $-0.246^{* * *}$ & $-0.219^{* * *}$ \\
\hline X49 & $0.128^{* * *}$ & $0.142^{* * *}$ & $0.146^{* * *}$ \\
\hline $\mathrm{X} 48$ & -0.036 & & \\
\hline $\mathrm{X} 47$ & -0.006 & & \\
\hline $\mathrm{X} 46$ & -0.039 & & \\
\hline $\mathrm{X} 45$ & -0.004 & & \\
\hline X44 & $0.068^{*}$ & $0.063^{*}$ & $0.053^{*}$ \\
\hline $\mathrm{X} 43$ & 0.081 & $0.078^{*}$ & 0.078 \\
\hline $\mathrm{X} 42$ & $-0.086^{* *}$ & $-0.104^{* * *}$ & $-0.091^{* *}$ \\
\hline $\mathrm{X} 41$ & $0.085^{* *}$ & $0.083^{* *}$ & $0.083^{* *}$ \\
\hline $\mathrm{X} 40$ & -0.026 & & \\
\hline X4 & $0.308^{* * *}$ & $0.315^{* * *}$ & $0.282^{* * *}$ \\
\hline
\end{tabular}


Table 3 (Continuation)

\begin{tabular}{|c|c|c|c|}
\hline Variable & OLS & Stepwise OLS & $S L M$ \\
\hline X39 & 0.035 & & \\
\hline X38 & $0.127^{* * *}$ & $0.127^{* * *}$ & $0.136^{* * *}$ \\
\hline X37 & 0.010 & & \\
\hline X36 & -0.026 & & \\
\hline $\mathrm{X} 35$ & $-0.081^{* *}$ & $-0.100^{* * *}$ & $-0.102^{* * *}$ \\
\hline X34 & $0.104^{*}$ & & \\
\hline X33 & -0.037 & & \\
\hline $\mathrm{X} 32$ & -0.020 & & \\
\hline X31 & 0.003 & & \\
\hline $\mathrm{X} 30$ & 0.033 & & \\
\hline X3 & -0.031 & & \\
\hline X29 & -0.077 & & \\
\hline $\mathrm{X} 28$ & 0.016 & & \\
\hline $\mathrm{X} 27$ & -0.031 & & \\
\hline X26 & 0.002 & & \\
\hline $\mathrm{X} 25$ & -0.009 & & \\
\hline $\mathrm{X} 24$ & -0.015 & & \\
\hline $\mathrm{X} 23$ & 0.028 & & \\
\hline $\mathrm{X} 22$ & $0.100^{*}$ & & \\
\hline $\mathrm{X} 21$ & $0.201^{* * *}$ & $0.206^{* * *}$ & $0.191^{* * *}$ \\
\hline $\mathrm{X} 20$ & $0.155^{* * *}$ & $0.172^{* * *}$ & $0.175^{* * *}$ \\
\hline $\mathrm{X} 2$ & $0.187^{* * *}$ & $0.180^{* * *}$ & $0.175^{* * *}$ \\
\hline $\mathrm{X} 19$ & $-0.025^{* *}$ & $-0.029^{* *}$ & $-0.029^{* *}$ \\
\hline X18 & -0.011 & & \\
\hline $\mathrm{X} 17$ & -0.032 & & \\
\hline $\mathrm{X} 16$ & 0.056 & & \\
\hline X15 & -0.050 & & \\
\hline X14 & 0.068 & & \\
\hline $\mathrm{X} 13$ & $0.001^{* * *}$ & $0.001^{* * *}$ & $0.001^{* * *}$ \\
\hline $\mathrm{X} 12$ & $0.104^{* *}$ & $0.115^{* * *}$ & $0.107^{* * *}$ \\
\hline X11 & $0.323^{* * *}$ & $-0.329^{* * *}$ & $-0.301^{* * *}$ \\
\hline $\mathrm{X} 10$ & 0.003 & & \\
\hline $\mathrm{X} 1$ & 0.118 & & \\
\hline
\end{tabular}

${ }^{*}$ significant at .10 level, ${ }^{* *}$ significant at .05 level and ${ }^{* * *}$ significant at .01 level Source: Own elaboration based on Yalcin (2016). 
According to the estimation results of the Spatial Lag Model obtained using the robust estimator in table 3 , the variables indicating whether the facility has a golf course and a sauna, the distance between the facility group and the sea with a distance ranging between 501 and 1000 meters, and the variables other than "sand type 2 " in the group determined as coarse sand were determined to be significant at .10 level. The explanatory variables of the model explain about $55 \%$ of the variations in the accommodation rates of the facilities in Antalya province.

\section{Table 4}

\section{The result report of the spatial autocorrelation of the room rate}

\begin{tabular}{lrrr}
\hline \multicolumn{1}{c}{ Variable } & OLS & Stepwise OLS & \multicolumn{1}{c}{ SLM } \\
\hline W_LNFYT $=\rho$ & & & $0.238^{* * *}$ \\
AIC & 2396.380 & 2352.268 & \\
SIC & 2744.542 & 2499.973 & \\
R-squared & 0.5572 & 0.5473 & \\
Adj. R-squared & 0.5363 & 0.5378 & \\
Pseudo R-squared & & & 0.5549 \\
Spatial Pseudo & & & 0.5478 \\
R-squared & & & \\
\hline
\end{tabular}

Source: Own elaboration based on Yalcin (2016).

Table 5

The LM test results

\begin{tabular}{lrc}
\hline \multicolumn{1}{c}{ Spatial dependence } & \multicolumn{1}{c}{ Value } & Probability \\
\hline Moran's I(error) & 6.307 & 0.000 \\
Log-Likelihood & -1148.134 & \\
LM (lag) & 28.899 & 0.000 \\
Robust LM (lag) & 10.619 & 0.001 \\
LM (error) & 21.658 & 0.000 \\
Robust LM (error) & 3.378 & 0.066 \\
LM (SARMA) & 32.277 & 0.000 \\
\hline
\end{tabular}

Source: Own elaboration based on Yalcin (2016).

The robust estimation results of the Spatial Lag Model seem to be statistically more significant compared to the results obtained by using OLS estimation. The value of the $\rho=w_{-}$LnRate coefficient has been determined to be 0.238 , which means that it is positive and significant 
and there is a strong autocorrelation. Besides the effects of these factors such as geographical location and environmental effects, the room rates of the accommodation facilities in Antalya province can also be said to have a relationship with the room rates in the neighboring locations. Accordingly, an increase of $1 \mathrm{TL}$ in the room rate of the neighboring facility leads to $0.238 \%$ increase in the room rate of the facility. This variable is one of the most effective variables in the model.

According to the results obtained, while having an outdoor pool increased the room rate by $0.19 \%$, having an indoor pool found to be insignificant in the model. Besides it, the variables that increase the room rate are determined to be the availability of laundry services, the availability of massage services, the number of rooms, the availability of the facility's private beach, having a snack bar in the facility, and being affiliated to a chain hotel group.

In the analysis, the dummy variables, X53, X54, and X55, which were obtained by measuring the distance between the facility and the sea, were found to be significant. The room rates of the facilities in the X53 group, which have a distance to the sea ranging from 101 to 500 meters, were found to have $0.09 \%$ lower rates than facilities having a distance to the sea ranging from 0 to 100 meters. And also, the room rates of the facilities in the X54 group, which have a distance to the sea ranging from 501 to 1000 meters were found to be $0.07 \%$ lower than the rates of the basic level group, and the room rates of the X55 group (the distance to the sea is more than 1000 meters) were determined to be lower by $0.13 \%$. It has been determined that the distance to the sea has a negative impact on the room rates. The room rates decrease in line with the locations of the accommodation facilities being away from the sea.

$\mathrm{X} 1$ and $\mathrm{X} 2$ are the concept variables which were designed to determine the effect of selected facility concepts on the room rates. The coefficient of the "half board/full board" facility concept in group X1 was found to be insignificant compared to the "room/bed and breakfast" concept, which has been defined as the base level. However, in the X2 group, the rates of the facilities with the concept of "all-inclusive/ultra-all-inclusive" were found to be $0.17 \%$ higher than those of the basic level group (bed and breakfast).

Variable groups about the facility types have been designed as base level (hotel/motel/boutique hotel/beach hotel), X3 (flat/suite/residence/ villa/pension/apartment), X4 (deluxe/all-in resort hotel/club/resort), X5 (guest house/palace/aparthotel/tree houses/bungalow/camping). The coefficient of the facilities categorized in $\mathrm{X} 3$ group is insignificant. However, the room rates of the facilities in the $\mathrm{X} 4$ group are $0.28 \%$ higher 
than those with the base level. The room rates of the facilities in the X5 group are $0.22 \%$ lower than those of the facilities with the base level.

Considering the effects of the beach properties on the room rates of the accommodation facilities, the variable X63, which indicates the width of the coast where the facility is located, was found to be significant and it reduced the room rate by $0.002 \%$. The variables indicating the sand type of the beach are categorized as the base level (fine sand), X64 (medium sand), X65 (coarse sand). The room rates of the facilities with a beach of medium sand type are $0.18 \%$ lower than those of the base level with a beach of fine sand. However, the effect of the variable of having a beach of coarse sand on the room rates of the facilities was found to be insignificant. That is, the beach of the facility had no importance since the beaches described as coarse sand are often rocky areas. In such regions, other aspects of the facilities become important. In a similar study, RigallI-Torrent et al. (2011) noted that the natural beaches had a negative impact on the room rates of the accommodation facilities; moreover, the coarse sand had a negative effect on room rates compared to the fine or very fine sand.

According to the model in table 3 , one of the most influential variable is the room type. Therefore, the variable group defining the room type was categorized into two groups as the standard room for 2 people (base level), and the other group (deluxe room/quin/superior for 2 people/ family room for 4-6 people/twin-bed bungalow villa). According to the results in table 3, the ROOM_TYPE variable was determined to be significant. In line with this result, the room rate for a deluxe room/quin/ superior/family room for 4-6 people/twin-bed bungalow villa for 2 people were found to be $0.30 \%$ lower than the room rates of the group with standard rooms for 2 people.

And also, in line with the results in table 3 , the variables affecting the room rates negatively are the number of languages spoken in the business, offering fax service in the facility, having an à la carte restaurant, and offering ironing service in the facility. This is because offering these services require new employment and additional costs to the accommodation facility. Increasing the number of languages spoken in the facility can be given as an example. Increasing the number of languages spoken can only be available by having new employees. And also, requiring new space and staff, the fax and ironing services are not usually demanded and cause additional costs. The à la carte restaurant is a feature that does not create much demand in the general sense in facilities of the region. Since the facilities in the region offer all-inclusive concepts, they eliminate the difference between similar food services. Moreover, providing an $\grave{a}$ la carte restaurant service will require additional space and employment 
and thus, additional costs will arise. Therefore, it can be considered that the number of languages spoken in the facility, offering fax service, having an à la carte restaurant, and offering ironing service have a negative impact on the room rates of the facility.

Since $\rho$ (rho) coefficient is also statistically significant and positive, it shows the presence of a positive autocorrelation. Thus, it means that the increase in the room rates of the facilities in the neighboring locations will lead to an increase in the rates in the relevant location. Moreover, the variables which were found statistically significant according to OLS results, such as having a golf course and offering newspaper service, were found insignificant according to spatial analysis. The golf courses cluster mostly in Belek region in the province of Antalya and many facilities in the province use the same golf course. Therefore, its impact on the room rates was determined to be spatially insignificant.

\subsection{Mapping of Exploratory Spatial Data Analysis Results}

The LISA maps facilitate understanding the spatial density visually and they are an important part of the spatial analyses. In this study, the LISA maps of the significant features of the facilities in table 3 based on the Spatial Lag Model were prepared by using QGIS software. The results obtained by using GeoDa software were used to map the data.

The feature of having an outdoor pool, which was determined to be significant, is a good example to assess spatial data analyses. Having an outdoor pool in the facilities is a variable that shows spatial interaction and gets influenced by the neighboring area. As a result, having an outdoor pool shows positive autocorrelation in Kemer, Beldibi, Göynük, Belek, Kızılot, Avsallar, and Mahmutlar regions and the facilities have an impact on each other with a high-high rate. There is a negative autocorrelation in other regions, they have a low-high impact on each other. In short, the outdoor pool of a neighboring facility has a positive impact on the other facilities that have an impact on each other with a high-high rate. A facility with an outdoor pool influenced the other facilities to have one (figure 4).

Examining the LISA map of the feature of having a private beach for a facility, a positive autocorrelation is observed in Beldibi, Belek, and Okurcalar regions and they are influenced by each other with a high-high rate. Moreover, Patara and Olimpos regions also show positive autocorrelations and they are influenced by each other with a low-low rate. There is a negative autocorrelation in the other regions and they have a low-high impact on each other. In short, the private beach of a neighboring facility has a positive impact on the other facilities that have an impact on each 


\section{Figure 4 \\ LISA Maps}
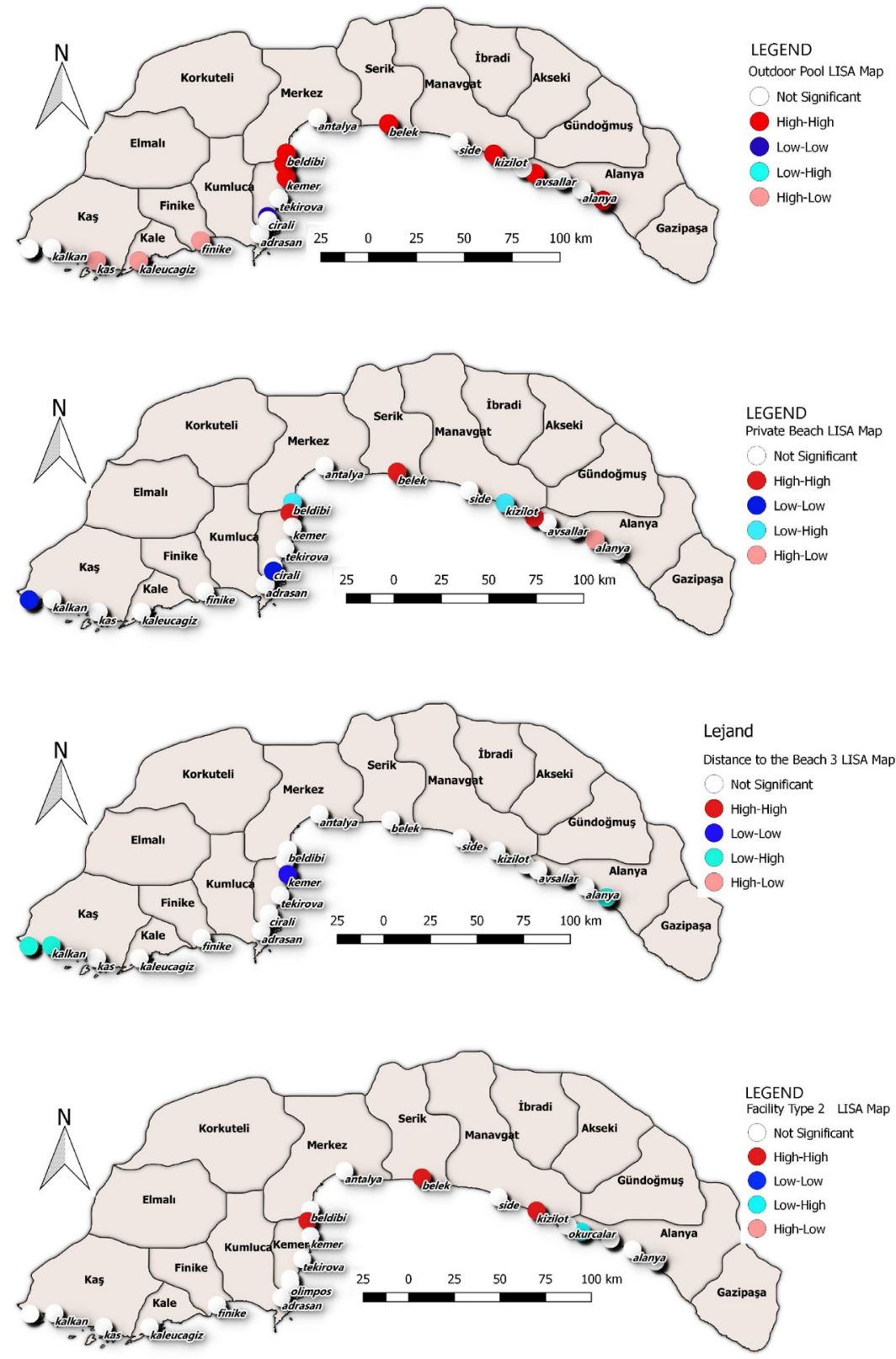

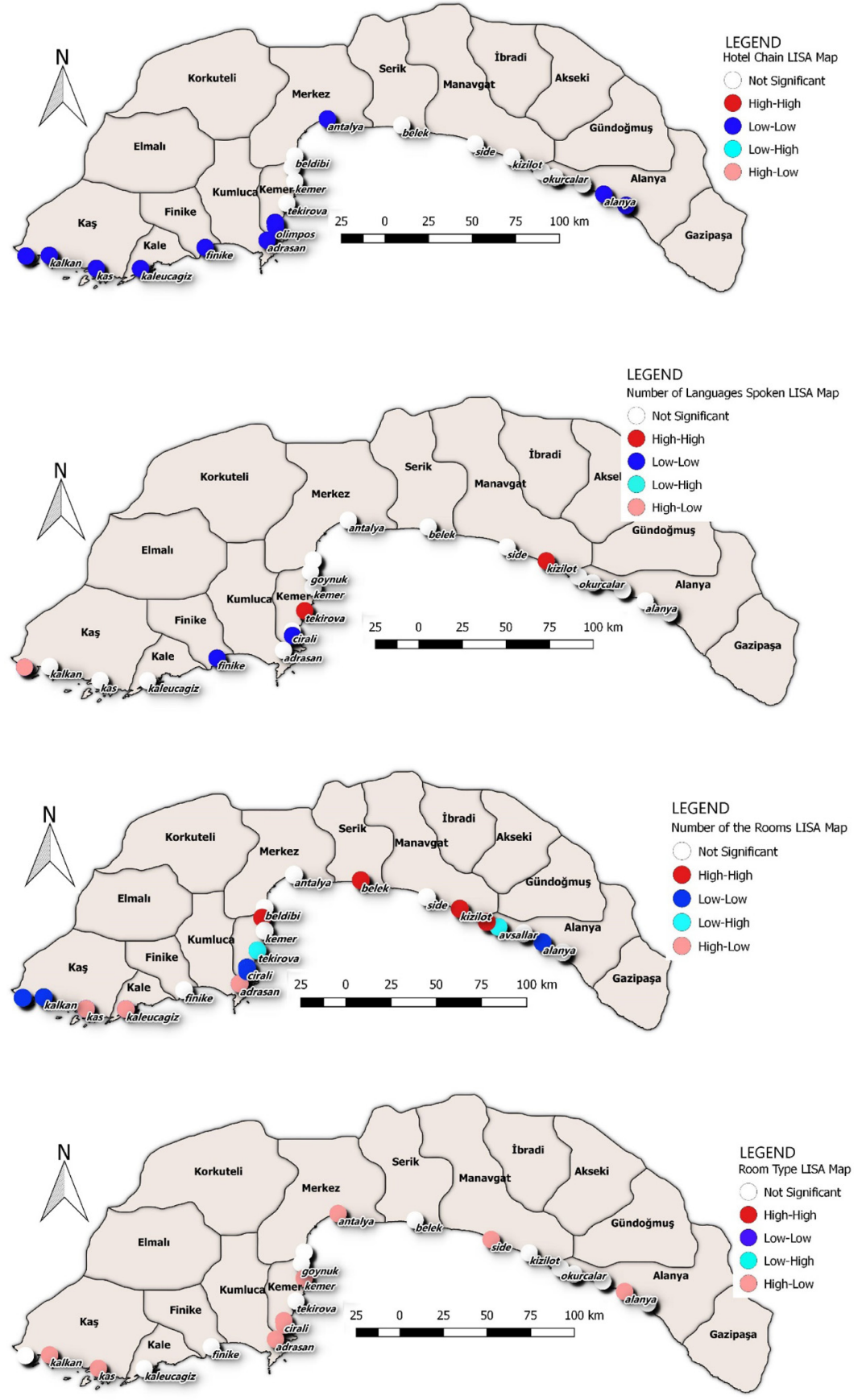

Source: own elaboration, generated using QGIS software. 
other with a high-high rate. A facility with a private beach influenced the other facilities to have one.

The LISA maps of the other variables can be seen in (figure 4).

\section{Conclusions}

In this study, it was tried to determine the features that have an impact on the room rates of 1,444 accommodation facilities in 21 tourism regions in Antalya province. Therefore, the physical characteristics of the facility and the features of the beach used by the facility have been examined whether there is a relationship between these features and the accommodation prices. The results showed that using spatially weighted regression method is more suitable than classical regression methods in the hedonic pricing models where the spatial impacts are considered to be higher. These results are consistent with the studies in the literature (Latinopoulos, 2018; Kostakis and Theodoropoulou, 2017; Hajilo et al., 2017).

The map showing the spatial distribution of the room rates has pointed out a spatial clustering. Moran-I scattering diagram and Moran-I coefficient have shown that the room rates are positively autocorrelated with room rates of the neighboring regions. In line with this, a spatial relationship has been determined between the room rates of the accommodation facilities in Antalya province. The LISA clustering map provided significant spatial clustering for neighboring locations in terms of accommodation prices.

At the end of examining the spatial distribution map, Moran-I test, and LISA analysis, a spatial interaction has been identified and 26 variables out of a total of 65 variables have been determined to be statistically significant by using stepwise regression analysis. At the end of the hedonic pricing model, which has been estimated by using stepwise regression analysis, the spatial autocorrelation tests have been carried out by using the residuals and the spatial weight matrix obtained. As a result, the spatial autocorrelation has been concluded to be due to the Spatial Lag Model.

Explanatory variables of the Spatial Lag Model explain about 55\% of the variations in the room rates of the accommodation facilities in Antalya province. According to the results of this model, the variables which have a significant contribution to the room rates of the accommodation facilities in Antalya province are the type of the facility, the change of the prices in the neighboring facilities, being affiliated to a hotel chain, having an outdoor pool, having a snack bar, having a private beach, laundry service, number of rooms, newspaper service, facility concept, massage, and the number of stars. The features which have a negative impact on 
the room rates are the room type, the sand type, the distance to the beach, fax service, à la carte restaurant, and the number of languages spoken in the facility.

Among the variables which have been found to be significantly effective on the room rates by the stepwise regression analysis, having a golf course and sauna, the medium sand type, the variables indicating the distance to the beach (the facilities with a distance ranging between 501 and 1000 meters to the beach), have been found to be statistically insignificant in accordance with the results of the Spatial Lag Model. To conclude, these variables have a significant effect on the room rates, but they have no spatial effect.

The robust predictor results of the spatial lag model obtained by the exploratory spatial data analysis have been determined to be statistically more significant compared to the results of the stepwise regression analysis. The value of the $\rho$ coefficient has been found to be 0.238 . Accordingly, the increase in the room rates of the neighboring enterprises leads to an increase in the room rates of the facility by $0.238 \%$. This variable is one of the most effective variables in the model.

The results of the study about the sand type of the beach used by the accommodation facility are consistent with the results of the study of RigallI-Torrent et al. (2011) on the impact of the beach features on the room rates in Catalonia/Spain. It has been determined that the room rates of the facilities with a beach of medium sand type are $0.18 \%$ lower compared to the accommodation prices of the facilities with beaches of fine sand. It has also been observed that the room rates get lower in line with being away from the beach. This situation implies the importance of the prediction coefficient of spatially weighted regression in the global modeling framework in which the spatial regression has been included in the hedonic pricing model. It has been revealed that this has been more innovative than the conventional methods in terms of room pricing of the accommodation facilities. The number of stars and the location of the facility have been determined to have a positive impact on the room pricing. The results of the study by Zhang et al. (2011) on the number of stars and the location of the facility have been consistent with the results of this study.

The studies about the coasts on which the accommodation facilities are located are important in terms of the strategic decisions taken by the operators of the accommodation facilities, the new investors, and the local governments. With this study, the parameters affecting the room rates of the facilities in Antalya province and their spatial relationship have been predicted. The facilities will be able to take appropriate measures based on their locations by using the obtained model. The features that have a higher impact on the accommodation prices will be considered and the 
other features will be improved accordingly. For new investors, the parameters specified in this model can be taken into account while deciding on the land on which the facility will be constructed.

In new studies, the distances from each accommodation facility to the city center and the airport can be included in the scope of the model.

\section{Acknowledgments}

This research was financially supported by the Scientific Research Projects Coordination Office of Akdeniz University in Turkey (BAP; SDK2016-1281).

\section{References}

Anselin, Luc (1995), "Local Indicators of Spatial Association-LISA", Geographical Analysis, 27, The Ohio State University, Rachel S. Franklin, Ohio, United State of America, pp. 93-115, doi: https:// doi.org/10.1111/j.1538-4632.1995.tb00338.x

Anselin, Luc (1992), "SpaceStat tutorial: a workbook for using SpaceStat in the analysis of spatial data", University of Illinois-Urbana-Champaign-Urbana, United States of America, <http://siteresources. worldbank.org/INTPGI/Resources/342674-1092157888460/ Anselin.spacestatTutorial.pdf>, April 5, 2018.

Anselin, Luc (1988), Spatial Econometrics: Methods and Models, Springer, Dordrecht, California, Santa Barbara, United States of America, <https://doi.org/10.1007/978-94-015-7799-1>, April 5, 2018.

Anselin, Luc, Bera Anil Kumar, Florax Raymond and Yoon Mann (1996), "Simple diagnostic tests for spatial dependence", Regional Science and Urban Economics, 26 (1), London School of Economics, London, England, pp. 77-104, doi: https://doi.org/10.1016/01660462(95)02111-6

Anselin, Luc, Kim Yong Wook and Syabri Ibnu (2004), "Web-based analytical tools for the exploration of spatial data" Journal of Geographical Systems, 6 (2), Springer Berlin Heidelberg, Vienna, Austria, pp. 197-218, doi: https://doi.org/10.1007/s10109-0040132-5 
Baddeley, Adrian (2017), "Local composite likelihood for spatial point processes", Spatial Statistics, 22 (2), University of Twente, Enschede, The Netherlands, pp. 261-295, doi https://doi. org/10.1016/j.spasta.2017.03.001

Basu, Sabyasachi and G. Thomas Thibodeau (1998), "Analysis of Spatial Autocorrelation in House Prices", The Journal of Real Estate Finance and Economics, 17 (1), University of Connecticut, United of State ofAmerica, pp. 61-85, doi:https://doi.org/10.1023/A:1007703229507

Brassington, Frances and Stephen Pettitt (2007), Essentials of Marketing 2nd edition, Pearson Education Limited, Edinburg Gate Harlow, England.

Bulchand-Gidumal, Jacques, Santiago Melián-González and Beatriz González Lopez-Valcarcel (2013), "A social media analysis of the contribution of destinations to client satisfaction with hotels", International Journal of Hospitality Management, vol. 35, Abraham Pizam, Universal Boulevard, Orlando, Florida, United States of America, pp. 44-47, doi: https://doi.org/10.1016/j.ijhm.2013.05.003

Bull, Adrian Osborn (1998), The effects of location and other attributes on the price of products which are place sensitive in demand, Griffith University, School of Economics, Faculty of International Business and Politics, Nathan, Australia, <http://195.130.87.21:8080/ dspace/bitstream/123456789/724/1/The\%20effects\%20of\%20 location\%20and\%20other\%20attributes\%20on\%20the $\% 20$ price\%20of.pdf>, April 5, 2018.

Chen Ching-Fu and Rochelle Rothschild (2010), "An application of hedonic pricing analysis to the case of hotel rooms in Taipei", Tourism Economics, 16 (3), SAGE Publishing, Los Angeles California, United States of America, pp. 685-694, <http://journals.sagepub. com/doi/pdf/10.5367/000000010792278310>, April 5, 2018.

Elhorst, Paul (2010), "Applied Spatial Econometrics: Raising the Bar", Journal Spatial Economic Analysis, 5 (1), Taylor and Francis, Groningen, The Netherlands, pp. 9-28, doi: https://doi. org/10.1080/17421770903541772 
Falk Martin (2008), "A hedonic price model for ski lift tickets", Tourism Management, 29 (6), Elsevier, Amsterdam, Holanda, pp. 11721184, doi: https://doi.org/10.1016/j.tourman.2008.02.021

Geary, Roberts Charles (1954), "The Contiguity ratio and statistical mapping", The Incorporated Statistician, 5 (3), Jstor, New York, United States of America, pp. 115-145, doi: http://www.jstor. org/stable/2986645

Hajilo, Mehdi, Mojtaba Ghadiri Masoom, Seyed Hassan Motiee Langroudi, Hassanali Faraji Sabokbar and Lori Pennington-Gray (2017), "Spatial analysis of the distribution of small businesses in the eastern villages of Gilan province with emphasis on the tourism sector in mountainous regions", Sustainability, 9 (12), Marc Rosen, Oshawa, Canada, pp. 1-19, doi: https://doi. org/10.3390/su9122238

Işık, Cem and Bilici Nilgün (2017), "The analysis of hotel room rates using hedonic model: the case of Erzurum", Journal of Graduate School of Social Sciences, 21 (1), Uluğ Mehmet, Odabaş Hüseyin, Sevindi Cemal, Kaya Mustafa, Erzurum, Turkey pp. 734-740

Kaya, Aslı and Murat Atan (2014), "Determination of the Factors that Affect House Prices in Turkey by Using Hedonic Pricing Model", Journal of Business, Economics and Finance, 3 (3), PressAcademia, Teker Dilek, Turkey, pp. 313-327, <http://www.pressacademia. org/images/documents/jbef/archives/vol_3_issue_3/04.pdf>, April 5, 2018.

Kostakis, Ioannis and Eleni Theodoropoulou (2017), "Spatial analysis of the nexus between tourism-human capital-economic growth", Tourism Economics, 23 (7), SAGE Publishing, Los Angeles California, United States of America, pp. 1523-1534, doi: https:// doi.org/10.1177/1354816617692473

Kördiş Gizem, Sayım Işık and Mehmet Mert (2014), "The Estimation of Determinants of House Prices in Antalya: Hedonic Pricing Model", (in Turkish) Akdeniz İI. B.F. Dergisi, nr.28, Çağatay Selim, Ateş Ayşegül, Antalya, Turkey, pp. 103-132, <http://dergipark.gov.tr/download/article-file/372819>, April 5, 2018. 
Lancaster, John Kelvin (1966), "A new approach to consumer theory", The Journal of Political Economy, 74 (2), JSTOR, New York, United States of America, pp. 132-157, doi: http://www.jstor.org/stable/ 182883

Latinopoulos, Dionysis (2018), "Using a spatial hedonic analysis to evaluate the effect of sea view on hotel prices", Tourism Management, nr. 65, Elsevier, Amsterdam, Holanda, pp. 87-99, doi: https:// doi.org/10.1016/j.tourman.2017.09.019

LeSage James (1999), The theory and practice of spatial econometrics, University of Toledo, Ohio, United States of America, <https://www. spatial-econometrics.com/html/sbook.pdf>, April 5, 2018.

Li, Chang, Guie Li, Yujia Zhu, Yong Ge, Hsiang-te Kung and Yijin Wu (2017), "A likelihood-based spatial statistical transformation model (LBSSTM) of regional economic development using DMSP/OLS time-series nighttime light imagery", Spatial Statistics, 21 (B), University of Twente, Enschede, The Netherlands, pp. 421-439, doi: https://doi.org/10.1016/j.spasta.2017.03.004

Manski, Charles (1993), "Identification of Endogenous Social Effects: The Reflection Problem", The Review of Economic Studies, 60 (3-1), Edinburgh University, Edinburgh, Scotland pp. 531-542, doi: https://doi.org/10.2307/2298123

MCT (Republic of Turkey Ministry of Culture and Tourism) (2003) "About Antalya City", Kültür ve Turizm Bakanlığı, Ankara, Turkey, <http://www.antalyakulturturizm.gov.tr/>, 14 March 2018.

Melián-González, Santiago, Jacques Bulchand-Gidumal and Beatriz González López-Valcárcel (2013), "Online Customer Reviews of Hotels as Participation Increases, Better Evaluation is Obtained", Cornell Hospitality Quarterly, 54 (3), Cornell University, New York, United States of America, pp. 274-283, doi: https://doi. org/10.1177/1938965513481498

Moran, Patrick Alfred Pierce (1950), "Notes on Continuous Stochastic Phenomena", Biometrika, 37 (12), Oxford University, London, England, pp. 17-23, doi: https://doi.org/10.2307/2332142 
Ord, John Keith and Arthur Getis (1995), "Local Spatial Autocorrelation Statistics: Distributional Issues and an Application", Geographical Analysis, nr. 27, Wiley Online Library, New Jersey, United States of America, pp. 286-306, doi: https://doi.org/10.1111/j.1538-4632.1995. tb00912.x

Papatheodorou, Andreas, Lei Zheng and Alexandros Apostolakis (2013), "Hedonic Price Analysis in Tourism Research", in Larry Dwyer, Alison Gill and Neelu Seetaram (eds.), Handbook of Research Methods in Tourism, Chapter: 2, Edward Elgar Publishing, Cheltenham, United Kingdom- Northampton, Massachusetts, United States of America, pp. 170-182, <https://www.researchgate.net/ publication/253327952_Hedonic_Price_Analysis_in_Tourism_Research?ev=auth_pub>, 14 March 2018.

Rigall-I-Torrent, Ricard, Modest Fluvià, Ramon Ballester, Alber Saló, Eduard Ariza and Josep-Maria Espinet (2011), "The effects of beach characteristics and location with respect to hotel prices", Tourism Management, 32 (5), Management School, Chris Ryan, Hamilton, New Zealand, pp. 1150-1158, doi: https://doi. org/10.1016/j.tourman.2010.10.005

Rosen, Sherwin (1974), "Hedonic prices and implicit markets: product differentiation in pure competition", Journal of Political Economy, 82 (1), University of Chicago Press, Chicago United States of America, pp. 34-55, doi: https://doi.org/10.1086/260169

Sánchez-Martín, José Manuel, Marcelino Sánchez-Rivero and Juan Ignacio Rengifo-Gallego (1998), "Analysis of the balance between tourist potential and suppy of rural tourism accommodation using spatial statitical techniques", Cuadernos de Turismo, nr. 39, Universidad de Murcia-Escuela Universitaria de Turismo, Murcia, España, pp. 547-702, doi: http://dx.doi.org/10.6018/ turismo.39.290701

TUIK (Turkish Statistical Institute) (2005), "Address-based population registration system", TUIK, Ankara, Turkey, <https://biruni.tuik. gov.tr/medas/?kn=95\&locale=tr>, 14 March 2018.

Uyar Sinem and Nihal Yayla (2016), "The estimation of housing prices within the frame of hedonic pricing approach by spatial econometric models: the case of istanbul housing market" (in Turkish), 
Social Sciences Journal, 11 (4), NWSA Academic Journals, Elazig, Turkey, pp. 326-342, doi: http://dx.doi.org/10.12739/NWSA $.2016 .11 .4 .3 \mathrm{C} 0153$

Wang, De-gen, Yu Niu and Jia Qian (2018), "Evolution and optimization of China's urban tourism spatial structure: A high speed rail perspective", Tourism Management, nr. 64, Elsevier, Amsterdam, Holanda, pp. 218-232, doi: https://doi.org/10.1016/j.tourman.2017.08.010

Ward, D. Michael and Kristian Skrede Gleditsch (2008), Spatial Regression Models (Quantitative Applications in the Social Sciences, SAGE publication, Los Angeles California, United States of America.

Yalcin, Fusun (2016), "Spatial analysis of the factors affecting the room price offered by the hotels in Antalya city" (in Turkish), Unpublished Doctorate Thesis, Akdeniz University, Graduate School of Social Sciences, Antalya, Turkey.

Zhang, Honglei, Jie Zhang, Shaojing Lu, Shaowen Cheng and Jinhe Zhang (2011), "Modeling hotel room price with geographically weighted regression", International Journal of Hospitality Management, nr. 30, Elsevier, Amsterdam, Holanda, pp. 1036-1043, doi: https://doi.org/10.1016/j.ijhm.2011.03.010

Recibido:20 de marzo 2018 Revisado:25 de mayo 2018. Aceptado:10 de julio 2018.

Fusun Yalcin. She has B.Sc. degrees in Mathematics from the University of Inonu, and M.Sc. degrees in Mathematics from the University of Nigde Omer Halisdemir, and Ph. D. degrees in Statistics (Econometrics) from the University of Akdeniz, Turkey. She is working as an Assistant Professor at Department of Mathematics, Faculty of Sciences, University of Akdeniz, Turkey. In addition, she is also teaching the applied Mathematics and statistics. She has published several papers and several presentations in international congress about applied Mathematics and statistics. Some of the latest publications are: Evaluation of heavy metal risk potential in Bogacayi River water (Antalya, Turkey), National Center for Biotechnology Information-National Library of Medicine, Bethesda, Washington, United States of America (2017), "Multivariate Analyses To Determine The 
Origin Of Some Polycyclic Aromatic Hydrocarbons (Pahs) In Honey Sample", Oxidation Communications, vol. 39, Balkan Tribo-logical Association for rapid scientific- Scientific Bulgarian Communication, Bulgarian, pp. 1547-1554 (2016), "Statistical Assessment of Heavy Metal Distribution and Contamination of Beach Sands of Antalya-Turkey: an Approach to the Multivariate Analysis Techniques", Filomat, vol. 30, Faculty of Sciences and Mathematics, University of Nis. Supported by the University of Nis, and by the Ministry of Education, Science and Technological Develpoment, Republic of Serbia, pp. 945-952 (2016) and "Principal Component Analysis of Integrated Metal Concentrations of Bogacayi Riverbank Sediments in Turkey", Polish Journal Of Environmental Studies, 25 (2), Bentus, Poznań, Poland, pp. 471-485 (2016)

Mehmet Mert. He has B.Sc. M.Sc. and Ph.D. degrees in Statistics from the University of Hacettepe, Turkey and has also worked as a Post Doctorate visiting professor in the University of Beira Interior, Portugal. Currently, he is working as an Associate Professor at Department of Econometrics, Faculty of Economics and Administrative Sciences, University of Akdeniz, Turkey. In addition, he is also teaching the time series analysis and applied econometrics courses at the Economics Department of Antalya Bilim University on part time basis. He has published several papers about recreation and tourism by using advanced econometrics on indexed journals, such as Social Indicators Research and several presentations in international congress. Some of the latest publications are: "Do foreign direct investment and renewable energy consumption affect the $\mathrm{CO} 2$ emissions? New evidence from a panel ARDL approach to Kyoto Annex countries", Environmental Science and Pollution Research, vol. 23, Springer, Berlin, Germany, pp. 21669-21681 (2016), "The renewable energy, growth and environmental Kuznets curve in Turkey: An ARDL approach", Renewable and Sustainable Energy Reviews, nr. 52, Elsevier, Amsterdam, Holanda, pp. 587-595 (2015) and "Fossil \& Renewable Energy Consumption, Ghgs (Greenhouse Gases) And Economic Growth: Evidence from A Panel of EU (European Union) Countries", Energy, vol. 74, Elsevier, Amsterdam, Holanda, pp. 439-446 (2014). 